\title{
Mutation in the Gene Encoding Sterol Regulatory Element Binding Protein (SREBP-2) in Hyper-Cholesterolaemic Subjects
}

\author{
Vivek Pratap Singh ${ }^{1}$, Nakul Sinha ${ }^{2}$, V. Ramesh ${ }^{3}$, Satyendra Tewari ${ }^{2}$, Faisal Khan ${ }^{1}$ \\ and Suraksha Agrawal ${ }^{1}$ \\ ${ }^{1}$ Department of Medical Genetics, ${ }^{2}$ Department of Cardiology, ${ }^{3}$ Department of Pathology, \\ Sanjay Gandhi Postgraduate Institute of Medical Sciences Raebareli Road, \\ Lucknow 226 014, Uttar Pradesh, India
}

KEYWORDS Mutations; missense mutation; SREBP-2 gene; hypercholesterolamia; Coronary artery disease

\begin{abstract}
The cholesterol homeostasis is regulated by the cleavage of membrane bound transcription factor sterol regulatory element binding proteins (SREBPs). We have analyzed 50 hypercholesterolaemic patients for genetic mutations in SREBP2 gene by direct sequencing of exon 5-10 of SREBP-2 gene that encodes the crucial functional domains. One missense mutation (V623M) in the regulatory domain was identified in the exon10 of SREBP-2 gene. However, no mutations were found in the regulatory domain in 200 controls samples. This is first report from India suggesting that the missense mutation (V623M) in human SREBP-2 gene may be true pathogenic mutations of hypercholesterolamic state.
\end{abstract}

\section{INTRODUCTION}

The end-product regulation of cholesterol metabolism is achieved predominantly through repression of transcription of genes that govern the synthesis of cholesterol and the genes of their receptors that are involved in their receptor mediated uptake from plasma lipoproteins. Two recently characterized proteins, designated as sterol regulatory element binding protein 1 and 2 (SREBP1 and SREBP2) that regulate transcription of HMG CoA reductase also regulate the LDL receptor, which supplies cholesterol through receptor- mediated endocytosis (Sakakura 2001).

The promoters of the LDL receptor genes are involved in the cholesterol and triglyceride homeostasis containing specific nucleotide sequences, sterol regulatory elements (SREs). In sterol regulated cleavage activation, SRE binding proteins (SREBP)- 1 and -2 bind to the SREs of the respective genes. The $\mathrm{NH}_{2}$ terminal domain, a mature and active form of the SREBPs, is released from the membrane by a two step proteolysis. First, the site 1 protease (SIP) cleaves SREBP and then sterol suppresses site 1 cleavage by interacting with a polytopic membrane protein

Corresponding Author: Dr. Suraksha Agrawal, Professor Department of Medical Genetics, Sanjay Gandhi Post Graduate Institute of Medical Sciences, Raebareli Road, Lucknow 226 014, Uttar Pradesh, India

Telephone: 091-522 -2668004-8 Ext 2338, 2346, 2347

Fax: 091-522 -2668973/2668017

E-mail: suraksha@sgpgi.ac.in designated SREBP cleavage-activating protein (SCAP). SREBP and SCAP interact in the ER membranes by their cytoplasmic $\mathrm{COOH}$-terminal domains (Sakai et al. 1998). In the second cleavage step, the site 2 protease (S2P) cleaves SREBP within the first trans-membrane segment and releases the $\mathrm{NH}_{2}$ terminal fragment of the SREBP precursor that enters the nucleus (Sakai et al. 1998). The binding of the $\mathrm{NH}_{2}$ terminal domain of SREBP to specific promoter elements result into the increase in the LDL receptor mediated uptake of LDL particles from the plasma and an increase in endogenous cholesterol biosynthesis.

Mutations in the genes encoding the SREBPs may result in inter-individual variations in plasma LDL-C levels. Since SREBP-2 rather than SREBP1, SREBP-1a and 1c, play a key role in cholesterol homeostasis, mutations particularly in SREBP-2 may have a major influence on plasma cholesterol concentrations (Miserez et al. 2002). However, no naturally occurring genetic variants in the gene encoding human SREBP-2 have been reported from India so far. In order to determine whether the genetic variants in SREBP-2, have any influence on plasma cholesterol concentrations, we have screened six different exons (exon5-10) of SREBP-2 gene that encode the crucial functional domains, for sequence variations in angiographically proven hypercholesterolaemic subjects and randomly selected healthy controls. 


\section{MATERIAL AND METHODS}

Subjects: A total of 50 consecutive patients were selected who were admitted for coronary angiography at SGPGIM, Lucknow for typical or atypical chest pain or post-myocardial infarction assessment. Diagnosis of CAD was considered on the basis of electrocardiographic or echocardiographic evidences proving myocardial infarction and also with obstructive lesions (e"50\%) on coronary angiography in any of the coronary arteries or their branches. All these 50 patients were hypercholesterolemic as diagnosed by the total serum being $>200 \mathrm{mg} / \mathrm{dl}$. A total of 200 age and sex matched healthy volunteers were also evaluated as controls.

PCR Amplification of Exons 5 to 10 of the Human SREBP-2 Gene: Each of the exon was amplified using specific flanking primers mentioned in Table 1. The PCR amplification for each locus was carried out. The amplicons were electrophorased at 2\% Agarose gel to confirm the amplification. The amplicons of each of the loci were then subjected for fluorescent ddNTP based automated DNA sequencing. The cycle sequencing was carried out for each of the amplicon using forward and reverse primers separately. The fluorescently labeled extension product was run on $\mathrm{ABI} 310 \mathrm{DNA}$ fragment size analyzer. Sequence alignment was carried out using CLUSTAL-X v1 software while the reference sequences were obtained from NCBI BLAST programme.

\section{RESULTS}

Screening of 250 subjects (50 hypercholesterolaemic patients and 200 controls) for sequence variations in exon 5 to 10 and the adjacent intron/exon junctions of the human SREBP-2 gene using direct sequencing revealed a point mutation in exon 10 . The biochemical analysis of the hypercholesterolaemic patients adjusted for age and gender revealed that mean plasma TC concentration was $204 \pm 85 \mathrm{mg} / \mathrm{dl}$.

Sequence data of exon 5, 6,7,8,9 revealed no mutations. However, a single base pair substitution in exon 10 of SREBP-2 gene was found in one of the 50 hypercholesterolaemic patients. This sequence variation was a single base pair substitution ( $\mathrm{G}$ to $A$ at a. a 623). Lipid analysis of the hypercholesterolaemic patient carrying the gene variant of SREBP-2 was associated with high level of total cholesterol $(321 \mathrm{mg} / \mathrm{dl})$, triglyceride (209 mg/dl) and LDL-cholesterol (152 $\mathrm{mg} / \mathrm{dl}$ ) concentration.

Multiple sequence alignment with the human, mouse, and Syrian hamster SREBP-2 sequences

Table 1: PCR conditions for the detection of sequence variations in exon 5-10 of the human SREBP-2 gene.

\begin{tabular}{|c|c|c|c|}
\hline Exon & Primer sequences & Product size (bp) & PCR cycling profile \\
\hline 5 & $\begin{array}{l}\text { F: cggaattctattctagaccetggtgggc } \\
\text { R: cggaattcgtacccaccttggcgtctgt }\end{array}$ & 278 & $\begin{array}{l}\text { Denaturing: } 95^{\circ} \mathrm{C} / 45 \mathrm{sec} \\
\text { Annealing : } 59^{\circ} \mathrm{C} / 30 \mathrm{sec} \\
\text { Extension : } 72^{\circ} \mathrm{C} / 45 \mathrm{sec} \\
\text { Cycles : } 32\end{array}$ \\
\hline 6 & $\begin{array}{l}\text { F: cggaattctggtctcactgtgtttcactcatc } \\
\text { R: cggaattcgccagggctgacaagcctttctca }\end{array}$ & 202 & $\begin{array}{l}\text { Denaturing: } 95^{\circ} \mathrm{C} / 45 \mathrm{sec} \\
\text { Annealing : } 57^{\circ} \mathrm{C} / 45 \mathrm{sec} \\
\text { Extension : } 72^{\circ} \mathrm{C} / 45 \mathrm{sec} \\
\text { Cycles : } 30\end{array}$ \\
\hline 7 & $\begin{array}{l}\text { F: cggaattcaaaagcagatcatttcaccaggtgggg } \\
\text { R: cggaattcctgtgacctcccagctatcttcttagggg }\end{array}$ & 313 & $\begin{array}{l}\text { Denaturing: } 95^{\circ} \mathrm{C} / 45 \mathrm{sec} \\
\text { Annealing : } 56^{\circ} \mathrm{C} / 30 \mathrm{sec} \\
\text { Extension : } 72^{\circ} \mathrm{C} / 1 \mathrm{~min} \\
\text { Cycles : } 30\end{array}$ \\
\hline 8 & $\begin{array}{l}\text { F: cggaattccacctcgaggccetttttggaggtcaa } \\
\text { R: cggaattccatagtggtccagccatgcccagg }\end{array}$ & 284 & $\begin{array}{l}\text { Denaturing: } 95^{\circ} \mathrm{C} / 45 \mathrm{sec} \\
\text { Annealing : } 60^{\circ} \mathrm{C} / 45 \mathrm{sec} \\
\text { Extension : } 72^{\circ} \mathrm{C} / 45 \mathrm{sec} \\
\text { Cycles : } 30\end{array}$ \\
\hline 9 & $\begin{array}{l}\text { F: cggaattcttccaaagagactctgctgagacga } \\
\text { R: cggaattcgggggaggatggggaagggcggaca }\end{array}$ & 268 & $\begin{array}{l}\text { Denaturing: } 95^{\circ} \mathrm{C} / 45 \mathrm{sec} \\
\text { Annealing : } 56^{\circ} \mathrm{C} / 30 \mathrm{sec} \\
\text { Extension : } 72^{\circ} \mathrm{C} / 1 \mathrm{~min} \\
\text { Cycles : } 32\end{array}$ \\
\hline 10 & $\begin{array}{l}\text { F: cggaattcgccagtgaccattaacaccttttga } \\
\text { R: cggaattctgcagcaagccagtcatcagcagct }\end{array}$ & 363 & $\begin{array}{l}\text { Denaturing: } 95^{\circ} \mathrm{C} / 45 \mathrm{sec} \\
\text { Annealing : } 59^{\circ} \mathrm{C} / 45 \mathrm{sec} \\
\text { Extension : } 72^{\circ} \mathrm{C} / 1 \mathrm{~min} \\
\text { Cycles : } 32\end{array}$ \\
\hline
\end{tabular}


revealed that valine at position $623(\mathrm{~V} 623 \mathrm{M})$ is conserved in all the three mammalian species.

\section{DISCUSSION}

Findings of the present study, based on the sequencing of exons 5 to 10 of SREBP2 gene in 50 hypercholesterolemic patients identified a point mutation in exon 10 . The exon 5 to 10 of the SREBP-2 gene encode DNA binding domain of the bHLH-zip, the two trans-membrane domains and the intervening intra-luminal loop, the two cleavage sites, and the adjacent part of the $\mathrm{COOH}$ terminal regulatory domain interacting with SREBP cleavage-activating protein (SCAP) (Brown and Goldstein 1997).

The sequence variation observed in the present study was a heterozygous single base pair substitution resulting into V623M amino acid change. The V623M mutation was absent in all the normal healthy controls screened. The observed frequency $(2 \%)$ is similar to the prevalence of $1.4 \%$ observed by Muller and Miserez, 2002 in their study on 70 hypercholesterolemic patients. Interestingly, we have not found any mutation in exon 6 and 7 which has been reported by Muller and Miserez, 2002 in both patients and controls. The V623M mutation observed in the present study is located in the $\mathrm{COOH}$-terminal domain of SREBP-2 that interacts with SREBP cleavage-activating protein (SCAP). Hence this missense mutation might reduce or even distort the interaction of SREBP-2 with the WD repeats of SCAP (Sakai et al. 1998). Considering the pivotal role of SCAP as an intra-membrane cholesterol sensor regulating the first sterol sensitive cleavage step of SREBP-2 (Sakai et al. 1998), an impaired interaction between SREBP-2 and SCAP would result in the decreased cleavage rate of SREBP-2. Consequently less transcriptionally active $\mathrm{NH}_{2}$ terminal fragments of SREBP2 would be released from the ER membranes and thus, enter the nucleus. As a result, this would lead to reduced transcriptional activation of SRE containing genes such as LDL receptor gene, which results into the decrease in the LDL receptor uptake of LDL particles from plasma and leads to hypercholesterolemia and may be one of the risk factor in causing coronary artery disease.
Formation of an SREBP-2.SCAP complex may be necessary for SREBP-2 to be cleaved at Site-1. Over expression of truncated $\mathrm{COOH}$-terminal domains of SREBP-2 or SCAP disrupted the SREBP-2.SCAP complex, under these conditions; SREBP-2 fails to be cleaved at site-1. The failure of SREBP cleavage leads to the decreased expression of SRE-dependent genes. Reduced transcriptional activation of SRE genes like LDL receptor gene causes a decrease in LDL receptor uptake of LDL, leading to hypercholesterolemia and risk of CAD.

Based on the absence of this missense mutation of the $\mathrm{COOH}$-terminal domain of SREBP-2 in the control subjects, its functional relevance and some earlier reports of its presence in Swedish hypercholesterolemic patients (Muller and Miserez 2002), we suggest that the V623M mutation may be one of the true pathogenic mutation leading to hypercholesterolemia. However, the findings require further validation by studying more subjects with hypercholesterolemia.

\section{ACKNOWLEDGMENTS}

Supported by grant from the Uttar Pradesh Council for Science and Technology (UPCST), Lucknow, India.

\section{REFERENCES}

Brown MS, Goldstein JL 1997. The SREBP pathway: Regulation of cholesterol metabolism by proteolysis of a membrane-bound transcription factor. Cell, 89: $331-340$

Miserez AR, Muller PY, Barella L, Barella S, Staehelin HB, Leitersdorf E, Kark JD, Friedlander Y 2002. Sterol-regulatory element-binding protein (SREBP)2 contributes to polygenic hypercholesterolemia. Atherosclerosis, 164: 15-26.

Muller PY and Miserez AR 2002. Identification of mutations in the gene encoding SREBP-2 in hypercholesterolaemic subjects. J Med Genet, 39: 271-275

Sakai J, Nohturfft A, Goldstein JL, Brown MS 1998. Cleavage of SREBPs at ste-1 requires interaction with SREBP cleavage-activating protein. Evidence from in vivo competition studies. J Biol Chem, 273: 5785-93.

Sakakura Y 2001 Sterol regulatory element-binding proteins induce an entire pathway of cholesterol synthesis. Biochem Biophys Res Commun, 286: 176- 183. 